\title{
BALEIAS E IMAGINÁRIOS: RUÍNA, RASGO E REPARAÇÃO EM TRÊS POEMAS BRASILEIROS CONTEMPORÂNEOS
}

http://dx.doi.org/10.11606/issn.2237-1184.v0i34p226-238

Diana Junkes ${ }^{I}$

\section{RESUMO}

Este artigo analisa, comparativamente, a construção e elaboração de uma mesma imagem, a baleia, em três poemas distintos, a saber: "Totem", de Ruy Proença, do livro Visão do térreo, de 2007; "respiramos como as baleias", de Prisca Agustoni, e "um enorme rabo de baleia" (2013), de Alice Sant'Anna. Para que as reflexões dirijam sua lupa para os versos e ao que eles nos trazem como forma e conteúdo, manifesto e manifestação estética, interioridade e exterioridade, realidade e imaginário, serão apresentadas reflexões sobre cada um dos poemas e, ao final, como um bordado, rasura, rasgo e reparação talvez digam mais sobre nós e sobre a poesia que nos habita, esta baleia imensa, ora totem ora asfixia, ora liberdade.

\section{ABSTRACT}

This article analyzes, comparatively, the construction and elaboration of the same image, the whale, in three different poems. The first poem is "Totem", by Ruy Proença, from the book Visão Térreo, from 2007. The second poem is by Prisca Agustoni and refers to the context of the pandemic. The third is by Alice Sant'Anna, "a huge whale's tail", published in Rabo de Baleia, 2013. The proposal is to read the poems so that reflections can direct their magnifying glass to the verses and to what they bring us as form and content, aesthetic manifesto and manifestation, interiority and exteriority, reality and imagination. Reflections on each of the poems will be presented and, in the end, like an embroidery, erasure, tearing, and repair, perhaps they will say more about us and about the poetry that inhabits us, this immense whale, sometimes totem, sometimes asphyxiation, sometimes freedom.

\section{PALAVRAS-CHAVE:}

Imaginário; Poesia;

Resistência; Utopia; Baleia.

\section{KEYWORDS}

Imaginary; Poetry; Resistance; Utopia; Whale.

\footnotetext{
I Universidade Federal de São Carlos, São Carlos, São Paulo, Brasil. 


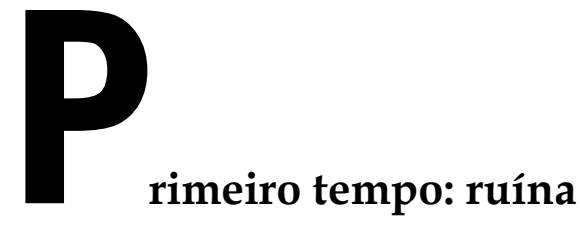

Em "Totem", poema de Ruy Proença (Visão do Térreo, Editora 34, 2007), a apreensão do objeto estético irrompe na amenidade do dia azul da praia, corrompendo as harmonias, os equilíbrios ao invadir de chofre a paisagem, o caminho à beira-mar, forçando a visão de todos em direção a si, como a criatura que aparece ao final de La dolce vita, de Fellini, olhos abertos ao nada, instaurando um pensamento paisagem, nos termos de Michell Collot, em que a paisagem provoca o pensamento e o pensamento se desdobra com paisagem, de tal modo que a "paisagem aparece, assim, como uma manifestação exemplar da multidimensionalidade dos fenômenos humanos e sociais, da interdependência do tempo e do espaço e da interação da natureza e da cultura, do econômico e do simbólico, do indivíduo e da sociedade" (COLLOT, 2013, p. 15). Desse modo, da baleia do poema é possível apreender toda uma forma de vida, de olhar e de estar na e com a paisagem que emana do sujeito lírico observador da cena. Em outras palavras, a baleia encena um corte - como ruína converte-se em objeto estético (SCOTT, 2019).

Totem

Uma baleia morta sobre a areia muda o centro de gravidade de um dia azul de cartão-postal.

As ondas perguntam e perguntam Por que se perdeu.

Apinhados ao longe os homens só sabem repetir em alvoroço o que as ondas perguntam.

Um homem se destaca dos demais:

19 metros, 40 toneladas brutal incerteza que aflora abalando o centro de um dia azul. (PROENÇA, 2007, p. 23).

O poema breve tem estrofes de tamanho irregular. Escrito em versos brancos e livres, quase simula uma notícia de jornal, mas é porque fica suspenso no quase que o sentido não se fecha. Não é uma constatação apenas, mas a partir dela, da ruína, o enfrentamento do incontornável, 
daquilo que entre o sujeito e o mundo, entre mar e areia torna-se limiar, uma necessária passagem, um atravessamento. Por isso a baleia é Totem. Não o Totem mítico ancestral em torno do qual se reúne uma coletividade (ainda que no poema as ondas e os homens em alvoroço pudessem sugerir esse coletivo), mas como ficcionalização, do mesmo modo que em Freud (ou seja, como um totem que se funda a partir do poema, o que está em jogo é o psiquismo, o sentimento do sujeito em relação ao animal tomado como totem que perturba o dia azul, sua estabilidade, sua paz). Mas aqui, ao contrário do Pai freudiano, que oscila entre o tabu e sua totemização, a baleia se torna um Totem porque talvez seja a chance mínima de salvação do dia azul - transcender a morte pelo totem.

Proponho a divisão do poema em três momentos. $\mathrm{O}$ primeiro momento coincide com a primeira estrofe. O segundo é composto pela segunda e terceira estrofes. $\mathrm{O}$ terceiro, pela última estrofe. No primeiro momento, a imagem que atravessa o olhar é de tal modo impactante que é sua responsabilidade (a da imagem, a da baleia morta) a mudança de centro da gravidade do dia azul como cartão postal. É bastante interessante avaliar como essa imagem arruína o dia, como se anunciará, por fim, ao final do poema ("Brutal incerteza que aflora/abalando o centro de um dia azul"). De início o que se tem é o sujeito fora do centro de gravidade - sem os pés no chão, ainda que simbolicamente. Como um rito de passagem sentido apenas interiormente, será preciso que essa gravidade outra, imposta pela gravidade da morte contornem a experiência até chegar a totem.

Uma baleia morta sobre a areia
muda o centro de gravidade
de um dia azul de cartão-postal.

A cena é bem construída, plástica, azul. A baleia é o elemento excêntrico que corrompe a harmonia do cartão-postal. Entre a leveza do dia azul e a fixidez da baleia morta, o centro de gravidade se altera, a baleia "encurva" o espaçotempo, recortando a paisagem com seu corpo imenso, imóvel, morto. Mais que invadir o dia azul, invade a perfeição do dia azul de cartão-postal, a melhor e irretocável imagem do equilíbrio, da harmonia, e por que não, do belo. Há um corpo morto, enorme e grotesco a invadir o sublime que azula tudo ao redor, denunciando a fragilidade da vida, a força do acaso, o avesso da ordem.

A baleia, portanto, desorganiza o dia, sob o olhar atento do sujeito lírico que descreve a cena. O enjambement entre os versos desta primeira estrofe sugere a própria circularidade do centro de gravidade alterado, mas, mais que isso, acompanhando a rasura que o cadáver traz à cena,

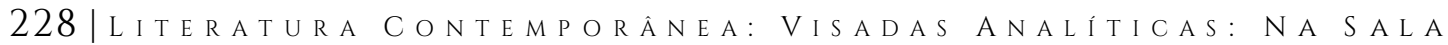


podemos pensar com Agamben de "A Ideia da Prosa" que o enjambement corrompe a poesia, instaurando o imponderável; nesse caso, imponderável que a morte inevitavelmente impõe. O enjambement não é poesia e nem prosa, instaura, pois, um discurso híbrido, tanto quanto o Totem não é mais o animal morto e nem sua possibilidade de vida, mas algo entre a vida e a morte. Assim enlaçam-se o título do poema, a elaboração da baleia morta, no expediente estético que transporta um verso ao verso seguinte.

Talvez seja por isso que na sequência, nas estrofes dois e três, as ondas entoem uma espécie de nênia, no que são acompanhadas pelos homens, violando o silêncio da própria baleia:

\author{
As ondas perguntam e perguntam \\ por que se perdeu. \\ Apinhados ao longe \\ os homens só sabem repetir em alvoroço \\ o que as ondas perguntam.
}

Nesta cena funeral, a voz das ondas, em sua eterna repetição, pergunta sobre o destino terminal da baleia. Vale notar o verso "As ondas perguntam e perguntam", cuja quebra aponta para a ausência de resposta, o branco da página, o silêncio da baleia perdida, encalhada à beira-mar, sobre a areia. Ainda que o questionamento se complete em termos sintáticos, no verso seguinte "por que se perdeu" é a abertura da pergunta que diz do imponderável mencionado logo acima.

As nasais em oNdas perguNtaM simulam o marulho das ondas, sua constância, de modo que para além do poema é possível pensar que as ondas trazem sempre a própria abertura ao que não se alcança e não se nomeia, o desejo, a vida, a morte, a finitude e a infinitude, uma nênia que possa "suturar a angústia", como aponta em algum momento DidiHurberman (2013). Nasalização que prossegue na estrofe seguinte em apiNHados, loNge, homeNs, sabeM, eM, oNdas, perguNtaM. Sim. Não apenas as nasais, mas as aliterações e vogais longas também compõem a nênia, em tom de lamento, com em "As OndAs [...] ApinhAdOs Ao lOnge/ Os hOmens sÓ sAbem repetir em AlvOrOçO e novamente em As OndAs".

Visual e auditivo o poema tensiona, por meio desses sentidos ativados pelo sujeito lírico que vê e ouve, a leveza e a imobilidade, também traduzidas pela bela imagem dos homens apinhados ao longe, talvez curiosos, porque se perguntam, em movimento de ir e vir, como as ondas por que a baleia se perdeu, talvez tristes ou ambos, aprofundando ainda mais a ruína desfazendo os azuis: 
Um homem se destaca dos demais:

19 metros, 40 toneladas brutal incerteza que aflora abalando o centro de um dia azul.

A descrição do tamanho da baleia, "19 metros, 40 toneladas", traz novamente à cena o grande mamífero que a câmera-olhar do sujeito lírico flagrou no primeiro verso, afastando-se depois para captar as ondas, os homens apinhados. É como se o olhar tivesse acompanhado todo o entorno para pousar novamente sobre a "brutal incerteza que aflora/ abalando o centro de um dia azul". No último verso, como nos versos da segunda e terceira estrofes, a nasalização e a assonância remetem ao imponderável mas também ao centro de gravidade abalado pela emergência ex-cêntrica da baleia sobre a areia.

Mas os dois últimos versos trazem algo a mais que a baleia - o mergulho existencial sobre a vida em si e a brutal incerteza com que é ameaçada pela morte, e então tudo se repropõe no dia azul abalado, rasurando as expectativas, a paisagem, qualquer conviç̧ão, mesmo a do incomparável dia azul, pois a baleia morta atesta que a aura pode se perder e é por isso que a totemização é fundamental, para que de algum modo, escondida, jacente, permaneça a aura, impregne a tarde. Dito de outro modo, é preciso converter a brutal incerteza que aflora, desvela a morte, a contingência, as ínfimas parcelas de vida disfarçadas sob a areia, no mar, em Totem para que a leveza tenha novas chances no dia azul. Como monumento, a baleia que brutalmente desconfigura a paisagem tem a existência assegurada entre a vida e a morte. $\mathrm{O}$ corpo da baleia se torna, assim, sua própria tumba e, nesse sentido, o sujeito lírico precisa ultrapassar, imaginariamente, a cisão que se abre diante dele no que o olha no que vê, de tal modo que o corpo perde sua evidência e o vazio que dentro dele habita perde "seu poder inquietante de morte". (DIDIHUBERMAN, 2013, p. 40).

Uma das forças do poema reside, a meu ver, no que Jean-Luc Nancy (2008) chamaria de acesso ao sentido, um acesso que se faz no difícil, daí a resistência da poesia. O poema não "resolve" a conversão do brutal corpo morto por uma morte tão aguda e pungente - o encalhamento do corpo pesado e irremovível na areia. Ao contrário, o título do poema propõe um acesso, entretanto, no corpo do poema, em que, como se disse, a própria corrupção da poesia pelo enjambement se coloca no sentido que aponta Agamben:

O enjambement exibe uma não-coincidência e uma desconexão entre o elemento métrico e o elemento sintáctico, entre o ritmo sonoro e o sentido, como se, contrariamente a um preconceito 
generalizado, que vê nela o lugar de um encontro, de uma perfeita consonância entre som e sentido, a poesia vivesse, pelo contrário, apenas da sua íntima discórdia. (AGAMBEN, 1999, p. 32)

Dessa forma, não só o poema, mas a vida, a tarde, vivem de sua "íntima discórdia" (AGAMBEN, 1999, p. 32). Íntima discórdia que extrapolando o enjambement será contrariada na conversão do homem em baleia na última estrofe. De um lado a rasura entre som e sentido aponta para a indecidibilidade, da morte, do acaso, do encalhamento à beira-mar. De outro, é o homem que encalha, que ao se converter (metamorfosear) em baleia aponta para uma abertura do sentido.

Nada está definido, será preciso atravessá-lo pela leitura e de novo e outra vez, perguntando-se, como o fazem as ondas, por que nos perdemos ou de algum modo por que em algum momento nos convertemos na imensa baleia morta, sob olhares atentos de bandos apinhados e vagas que entoam nênias. Ao fim e ao cabo são tentativas de tradução do fato, como se uma busca incessante por um original fosse rasurando e rasurando a origem - a baleia viva - irrecuperável a não ser por aquilo que, como rastro e resto deixa sob o olhar, na tarde azul de cartão-postal a placidez da ruína, um homem-baleia. Veja acima.

\title{
2. Segundo tempo: rasgo
}

Em "respiramos como as baleias", de Prisca Agustoni, não se tem mais a ruína no dia azul, mas a asfixia, as pessoas arpoadas, o fundo sombrio a que nos conduz este tempo pandêmico. Se no poema anterior o olhar e a audição eram prevalentes, aqui o sujeito lírico sucumbe pela pele, pelo tato e por meio da propriocepção que o faz saber-se no abismo, escuro, profundo e sem saída. Assim, neste poema a experiência é cindida, rasgada e irreparável, o poema não parte da morte, mas chega a ela. Da ruína ao rasgo aprofunda-se a relação do sujeito lírico com a morte e não só isso, deflagra-se sua morte com dor, arpoado.

\author{
respiramos como as baleias \\ através das guelras do prédio \\ a cada movimento \\ é a calmaria do oceano \\ que ondula, \\ as cristas são escamas \\ que se roçam e se tocam
}

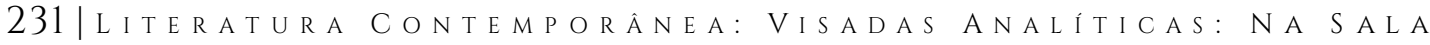




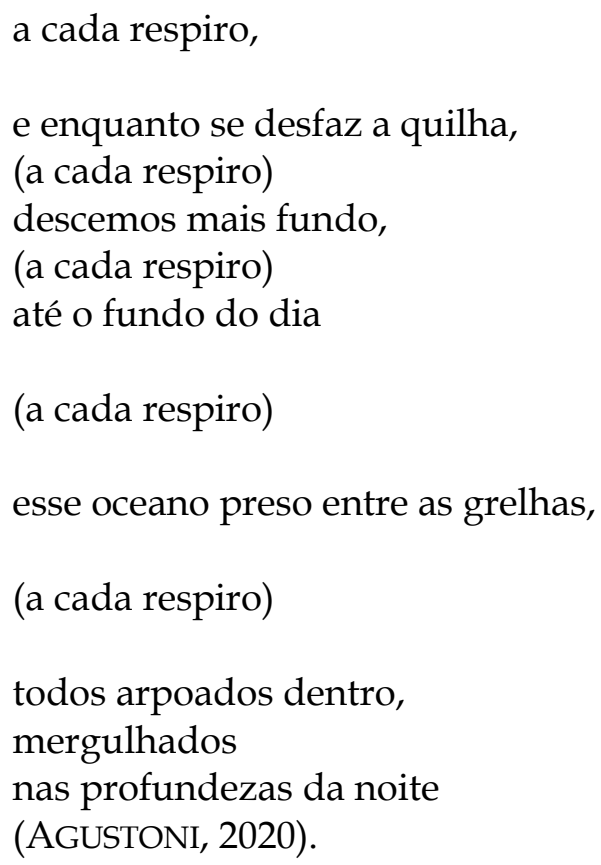

Logo no primeiro verso, o poema nos apresenta as baleias e de imediato o símile - nós é que respiramos como elas, mergulhados em edifícios, cujas janelas-guelras garantem a entrada e a saída de ar. Baleia que é cetáceo e é peixe, a quem falta ar e a quem é dado ter guelras. $\mathrm{Na}$ fusão humano-baleia, também o prédio se amalgama, tem guelras. $O$ prédio é o grande corpo da baleia mergulhado na cidade, corpo que ondula a cada inspiração e expiração, não mais a baleia-totem do poema de Ruy Proença, mas a baleia concreto, concreta, que, se de início é circundada pela calmaria e pela ternura do roçar das escamas, depois vai afundando, ferida, "(a cada respiro)".

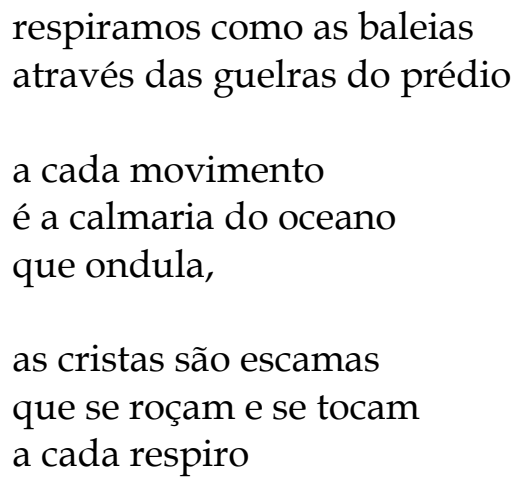

Tudo no poema é fusão. Da baleia ao prédio, do prédio ao oceano, das cristas das ondas às escamas que se tocam e se roçam como se estivéssemos assistindo a um filme de Jodorowsky, em que o sonho e a realidade se confundem a cada respiro. Mas a partir deste ponto, o tom onírico vai sendo penetrado pela força de outras comparações, a calmaria, 
o ar que as guelras absorvem e expulsam passa assumir um tom angustiante, junto com ele a noite que substitui o toque das escamascristas. A cada respiro:

\author{
descemos mais fundo, \\ (a cada respiro) \\ até o fundo do dia \\ (a cada respiro) \\ esse oceano preso entre as grelhas, \\ (a cada respiro)
}

Como um refrão, ou o intervalo da respiração cada vez mais difícil, o verso agora surge entre parênteses, como se estes fossem aparelhos a garantir a respiração. O corpo vai se aprisionando cada vez mais, e cada vez mais em abismo perde o ar. Note-se o espaçamento dos versos, entre (a cada respiro), circunscrito, espaçado, não mais fechando a estrofe depois das escamas que se roçam e tocam, mas em trajetória descendente até o fim do dia: "descemos mais fundo (a cada respiro)/até o fundo do dia//(a cada respiro). A reiteração de fundo não pode deixar de ser notada aqui, como se um sentimento de vazio, um oco, fosse respaldando o movimento das guelras, nossas guelras, que nos fazem respirar como baleias, que não têm guelras.

Desse modo, entre os peixes com escamas que respiram sob as águas e as baleias, cetáceos de sangue quente, que precisam subir à superfície para respirar e é este o movimento que não são capazes de fazer, tolhidas da possibilidade de vir à tona, aprisionadas nos edifícios, as baleias, nós mesmos, (a cada respiro) perdemos um pouco do ar, em descida agônica, no "oceano preso entre as grelhas". Mais uma vez a imagem que ultrapassa os limites do real ou que o questiona atua para compor a cena poética até o desfecho:

\author{
todos arpoados dentro, \\ mergulhados \\ nas profundezas da noite
}

"Nós" que respirávamos na calmaria agora feridos, arpoados dentro, avançamos em mergulho pela noite, nas profundezas da morte. Esse belo poema desenha com delicadeza e contundência as sombras que atravessamos em meio à covid-19. De repente a casa, as janelas do prédio, as guelras fecham-se em mergulho abissal. O fundo do dia é também o

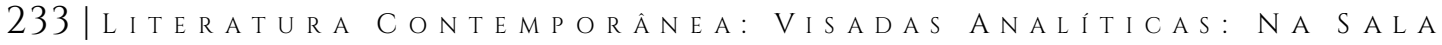


isolamento a que todos estão sujeitos, diz da impossibilidade do roçar de peles, cristas-escamas.

No solitário mergulho, (a cada respiro) o sujeito - que é sempre coletivo neste poema - dá-se conta da condição de arpoados em que estão todos e todas a seu redor. A baleia aqui não encalha na areia para arruinar o dia azul de cartão-postal, mas arpoada rasga o dia, a noite, em direção ao nada, quando há só grelhas e o fundo do fundo de um oceano-cidade tomado de dor, de perdas e ausências. Este é também um poema sobre o silêncio, mesmo que nada se soubesse sobre o contexto de sua produção e que neste caso é importante para a construção dos sentidos. É um poema sobre o silêncio porque aos poucos as estrofes vão se rarefazendo, os parênteses impõem limites ao dizer, ao ar que entra nos pulmões, até que não haja mais nada a dizer.

Se no primeiro poema o eu-lírico vive a ruína, aqui ele é rasgado pela dor - a ruína viria depois, se o poema continuasse. E é porque vive da dor que não é possível narrar as grelhas do oceano, o fundo do fundo do dia. Então, da perspectiva benjaminiana o poema é sobre a pobreza da experiência e sobre o recolhimento dos sujeitos, arpoados mergulhando na profunda noite da história, condenados ao silenciamento (Benjamin, 1996). Então, aqui, a baleia, mais que imagem ou símbolo, é uma alegoria: "Quando, sob o olhar da melancolia, o objeto se torna alegórico, quando ela lhe retira a vida, ele permanece morto, mas salvo na eternidade, assim se apresenta o objeto [...]. Quer dizer, de agora em diante é totalmente incapaz de irradiar uma significação, um sentido, tem o sentido que o alegorista lhe dá". (Benjamin, 1986, p.36)

E o que alegoriza a baleia? A morte, ou talvez fosse mais preciso dizer a impossibilidade da vida. Pelo véu com que ela encobre o objeto poema, entrevê-se um modo de estar na cultura diante da barbárie, os corpos devastados, o próprio tempo em que a poeta está mergulhada na poeta.

\section{Terceiro tempo: reparação}

Ao contrário dos poemas anteriores em que a baleia se associa à morte, à brutal incerteza, à falta de ar no corpo arpoado, no poema de Alice Sant'Anna publicado em Rabo de baleia (Cosac\&Naify, 2013), a baleia não é ruína ou rasgo, mas reparação, capaz de refazer fendas, livrar do tédio, conduzir o sujeito lírico para além de si, escapando do cotidiano. Se no poema de Ruy Proença a baleia é estanque, se em Prisca Agustoni, mergulho no abismo sob forte dor, aqui é liberdade, encontro, a possibilidade de outros mundos possíveis que restaure o desejo, a partilha, a própria poesia. Como nos dois poemas anteriores, a circularidade traz a 
baleia no início e no final do poema, mesmo que metonimicamente, em Agustoni pelo "arpoados", que se refere à baleia arpoada, em Proença pelos "19 metros, 40 toneladas", referindo-se ao tamanho da baleia, e no enorme rabo de baleia em Sant'Anna.

\author{
um enorme rabo de baleia \\ cruzaria a sala nesse momento \\ sem barulho algum o bicho \\ afundaria nas tábuas corridas \\ e sumiria sem que percebêssemos \\ no sofá a falta de assunto \\ o que eu queria mas não te conto \\ era abraçar a baleia mergulhar com ela \\ sinto um tédio pavoroso desses dias \\ de água parada acumulando mosquito \\ apesar da agitação dos dias \\ da exaustão dos dias \\ o corpo que chega exausto em casa \\ com a mão esticada em busca \\ de um copo d'água \\ a urgência de seguir para uma terça \\ ou quarta boia e a vontade \\ é de abraçar um enorme \\ rabo de baleia seguir com ela \\ (SANT'ANNA, 2013).
}

Neste poema escrito em um único bloco, o corpo é a medida do sonho, um plano arquitetado em silêncio, uma rota de fuga. Aqui não é a baleia que atravessa a vida, a rotina, o isolamento ou o dia azul do cartãopostal, a alegoria da morte, mas o desejo do sujeito lírico que a coloca no cotidiano. Não é uma baleia-símile, mas uma baleia inventada na fantasia, carregada, portanto, da verdade do sujeito, da potencialidade de seu imaginário e, como tal, concebida de modo a reparar o tédio, a desilusão, a sede que a mão em busca do copo d’água não consegue saciar.

um enorme rabo de baleia

cruzaria a sala nesse momento

sem barulho algum o bicho

afundaria nas tábuas corridas

e sumiria sem que percebêssemos

no sofá a falta de assunto

O título do poema "um enorme rabo de baleia" compõe o sentido da leitura, mas sendo título, o intervalo entre ele e o primeiro verso marca o 
imaginário que começa a se insinuar, a própria hesitação do sujeito diante da fantasia que vai se delinear logo adiante - uma abertura à contingência, situada entre imaginário e simbólico para, em seguida, completar-se na linguagem da poesia "cruzaria a sala nesse momento". O rabo de baleia é o próprio desejo, encoberto sob as tábuas corridas ante a falta de diálogo, testemunhada pelo sofá. Se nos poemas anteriores a existência da baleia era incontornável, aqui, é movendo-se em silêncio que entre os vãos penetra, como se fosse feita de sonho:

\author{
o que eu queria mas não te conto \\ era abraçar a baleia mergulhar com ela \\ sinto um tédio pavoroso desses dias \\ de água parada acumulando mosquito \\ apesar da agitação dos dias \\ da exaustão dos dias
}

E então vem a interrupção pela voz deste eu-lírico entediado ao extremo: "o que eu queria mas não te conto/era abraçar a baleia mergulhar com ela". À rotina opressora opõe-se a vontade de abraçar a baleia e mergulhar com ela. Esse ponto é importante porque mais à frente o desejo será seguir com a baleia, em gradação ao que se aponta aqui. As imagens do poema oscilam entre a imobilidade e a agitação típicas de um tempo dromocrático, ou seja, dominado pelo império da velocidade, que se governa pelo imediatismo, pela velocidade e se opõem ao movimento livre da cauda da baleia: "água parada acumulando mosquito"; "agitação dos dias"; "exaustão dos dias".

Também é importante marcar que esse sonho acalentado secretamente ("o que eu queria mas não te conto") torna ainda mais potente a vontade de romper com o estado das coisas e rumar com a baleia, ser levado por ela. Vontade de deixar este ao lado de quem a falta de assunto mitiga o aconchego do sofá e mata de sede.

No trecho seguinte a oscilação fica mais evidente - face a uma vida regida pelo trabalho ("o corpo que chega exausto em casa"), pela urgência no âmbito doméstico o que se tem é o tédio, a paralisia, a urgência da fuga, a mão sedenta de afeto, de conversa (lembremos da falta de assunto no sofá):

o corpo que chega exausto em casa

com a mão esticada em busca

de um copo d'água

a urgência de seguir para uma terça

ou quarta boia e a vontade

é de abraçar um enorme

rabo de baleia seguir com ela

236 | Literatura CONTEMPORÂNEA: VISADAS ANALÍticas: NA S A L A 
A vida é agreste aqui. Não há diálogo e há sede, a água é parada e acumula mosquitos. O corpo exausto. Então a baleia é a metáfora da liberdade, ao mesmo tempo que figurativiza o desejo de liberdade: "abraçar e mergulhar"; "abraçar um enorme rabo de baleia" (que retoma o título) para seguir com ela.

Disse no início desta seção que este era o "tempo" da reparação. $O$ poema é sobre a falta de amor e de afeto, corpos que não se encontram, braços estendidos, "urgência de seguir para uma terça ou quarta boia". E o que é que repara esta falta senão a baleia? A possibilidade de escape em primeiro lugar, pela via do imaginário, depois o escape pela via do reconhecimento do desejo de fugir - "o que eu queria mas não te conto". Por fim, o que é reparador é a poesia em si, extrapolando o rabo de baleia e situando na e pela linguagem as possibilidades de sonho, elaboração e criação de meios que tornem viáveis e suportáveis a vida. Mas reparar é também restituir ao sujeito possibilidades de uma existência outra - a reparação não anula o dano, ou a dor e perda, mas pode viabilizar a ressignificação da própria experiência. Evidentemente do ponto de vista social, não há reparação aqui. Ao contrário, o que haverá é a mesma ausência no sofá e a mesma sede no dia seguinte. Transferindo, porém, a crueza da análise social para o que o poema em si traz como constituição de uma outra verdade para o sujeito, a partir da criação, da delicadeza e da multiplicidade - o deslocamento se afirma fortemente e é aí onde antes o vazio latejava que o desejo passará a ocupar lugar preponderante, como resistência, pela poesia. Diz Jean-Luc Nancy:

\footnotetext{
Aquilo a que chamei aqui a "resistência" da poesia seria em suma a resistência da linguagem à sua própria infinitude (ou indefinitude segundo o valor exato que será dado ao infinito). A resistência à desmedida que a linguagem é por si mesma e por conseguinte uma resistência inscrita na linguagem, mas no seu reverso ou como seu reverso (NANCY, 2008, p. 42).
}

É preciso dar à falta que nos é constitutiva a ilusão de que a falta é preenchida, até que o desejo se esgote ou se desloque, ou se reacenda. Resistir é preencher faltas. Sem esse jogo de perde-ganha os movimentos e reverberações da alma perdem os acordes, os compassos, o tempo certo de afundar entre as tábuas corridas, abraçar a baleia e seguir com ela, não importa para onde, pois é no seguir que se redescobre que navegar é preciso: sobre o dorso das baleias, no acalanto do seu canto e na persistência lúdica de seus esguichos, ou simplesmente agarrando seu enorme rabo para ir aonde a medida da resistência da poesia puder levar, ao verso, ao ritmo, à "vida e seu ofício". E esse movimento, não podemos

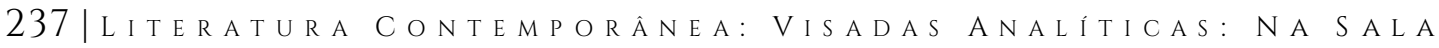
D E A U L A 
deixar de colocar aqui, diz também do que seja a poesia. Um jogo de perdeganha em que o fim não é a procura do sentido final, mas a compreensão de que o sentido está na travessia da leitura, configurada pela jornada do leitor no périplo do poema, pelo percurso analítico que o caminhante leitor desvela.

\section{Referências bibliográficas}

AgAmben, Giorgio. A ideia da prosa. In: A ideia da Prosa. Tradução, prefácio e notas de João Barrento. Lisboa: Cotovia, 1999, p. 30-34.

AGUSTONI, Prisca. "como baleias respiramos". Poemas inéditos [mimeo], 2020-2021.

BENJAMIN, Walter. Alegoria e drama barroco. In: Documentos da cultura, documentos da barbárie. Organização e seleção de Willi Bolle. Tradução de Bolle et al. São Paulo: Cultrix, 1986, p. 17-41.

COLlot, Michel. Poética e filosofia da paisagem. Tradução de Ida Alves. Rio de Janeiro: Oficina Raquel, 2012.

DiDI-HubERMAN, George. O que vemos, o que nos olha. Tradução de Paulo Neves. São Paulo: 34, 2013.

GREIMAS, Algirdas Julien. Da imperfeição. Tradução de Ana Claudia Oliveira. São Paulo: Estação das Letras e Cores, 2002.

NANCY, Jean-Luc. A resistência da poesia. Tradução de Bruno Meira. Lisboa, Vendaval, 2002.

ProençA, Ruy. Totem. In: Visão do térreo. São Paulo: 34, 2007.

SANT'ANNA, Alice. "um enorme rabo de baleia". In: Rabo de baleia. São Paulo: Cosac Naify, 2013.

SCOTT, Diane. Ruine: invention d'um objet critique. Paris: Les Praires Ordinaires, 2019.

Diana Junkes é professora na Universidade Federal de São Carlos e bolsista de produtividade do CNPq. Publicou As razões da máquina antropofágica: poesia e sincronia em Haroldo de Campos (crítica literária, EdUnesp, 2013). Contato: dijunkes@ufscar.br

ORCiD: https://orcid.org/0000-0002-5465-8030 